\title{
GDNF and protection of adult central catecholaminergic neurons
}

\author{
Alberto Pascual ${ }^{1,2}$, María Hidalgo-Figueroa ${ }^{1,2}$, Raquel Gómez-Díaz ${ }^{1,2}$ \\ and José López-Barneo ${ }^{1,2}$ \\ ${ }^{1}$ Instituto de Biomedicina de Sevilla, Hospital Universitario Virgen del Rocío/CSIC/Universidad de Sevilla, Avenida Manuel Siurot s/n, 41013 Sevilla, Spain \\ ${ }^{2}$ Centro de Investigación Biomédica en Red sobre Enfermedades Neurodegenerativas (CIBERNED), Sevilla, Spain \\ (Correspondence should be addressed to A Pascual at Instituto de Biomedicina de Sevilla, Hospital Universitario Virgen del Rocío/CSIC/Universidad de Sevilla, Avenida Manuel Siurot \\ s/n, 41013 Sevilla, Spain; Email: apascual-ibis@us.es; J Lopez-Barneo at Instituto de Biomedicina de Sevilla, Hospital Universitario Virgen del Rocío/CSIC/Universidad de Sevilla, \\ Avenida Manuel Siurot s/n, 41013 Sevilla, Spain; Email: Ibarneo@us.es)
}

\begin{abstract}
Neurotrophic factors are small proteins necessary for neuron survival and maintenance of phenotype. They are considered as promising therapeutic tools for neurodegenerative diseases. The glial cell line-derived neurotrophic factor (GDNF) protects catecholaminergic cells from toxic insults; thus, its potential therapeutic applicability in Parkinson's disease has been intensely investigated. In recent years, there have been major advances in the analysis of GDNF signaling pathways in peripheral neurons and embryonic dopamine mesencephalic cells. However, the actual physiological role of GDNF in maintaining catecholaminergic central neurons during adulthood is only starting to be unraveled, and the mechanisms whereby GDNF protects central brain neurons are poorly known. In this study, we review the current knowledge of GDNF expression, signaling, and function in adult brain, with special emphasis on the genetic animal models with deficiency in the GDNF-dependent pathways.
\end{abstract}

Journal of Molecular Endocrinology (2011) 46, R83-R92

\section{Introduction}

Neurotrophic factors (NTFs) are small natural proteins necessary for the development and survival of nerve cells as well as for the maintenance of their morphological and functional phenotype. The 'neurotrophic hypothesis' enunciates that the establishment and maintenance of neuronal networks require the release at the target structures of NTFs, which are uptaken by the nerve terminals and retrogradely transported to the soma of the projecting neurons (Ibanez 2007). Upon reaching the nucleus, NTFs induce a gene program that promotes neuronal survival and phenotype specification. Although the existence of 'chemotactic' influences between the growth cones of axons and their targets was already postulated by Cajal's group (Cajal 1928), the modern concept of neurotrophism is based on the work of Hamburger \& Levi-Montalcini (1949) who reported that the switch from cell survival to death observed during brain development depended on substances produced at the site where neurons were projecting, hence removal of a prospective target dramatically increased neuronal loss.
During the last decades, several proteins have been classified as NTF because of their effect on neuronal survival, differentiation (including synaptogenesis and neurite branching in vitro), maturation of electrophysiological properties, and plasticity. Due to their functional roles, NTFs are considered a promising tool to treat neurodegenerative diseases (Kirik et al. 2004), and particularly Parkinson's disease (PD), a neurodegenerative disorder characterized by motor symptoms (tremor, bradykinesia, rigidity, and alteration of gait) (Lang \& Lozano 1998, Fahn 2003) which affects over one million Europeans (de Rijk et al. 1997, de Lau \& Breteler 2006). The etiology and pathogenesis of PD are essentially unknown, although several causative mechanisms, including alterations of protein folding/ degradation, mitochondrial dysfunction and oxidative stress, neuroinflammation, and $\mathrm{Ca}^{2+}$ excitotoxicity have been proposed (Dauer \& Przedborski 2003, Farrer 2006). PD is caused by the progressive loss of specific sets of neurons both in the brainstem and in the peripheral nervous system. From a clinical standpoint, the most critical neuronal population affected corresponds to the midbrain dopaminergic (DA) neurons in 
the substantia nigra (SN) pars compacta projecting to the striatum (nigrostriatal neurons), thus leading to dysfunction of the neuronal circuits in the basal ganglia and alteration of motor control. DA neurons in the neighboring ventral tegmental area (VTA) are less affected than SN neurons. Although the loss of nigrostriatal DA neurons is the most apparent pathological hallmark of PD, other cell types are affected even before SN cell death. Among those are the noradrenergic neurons in the locus coeruleus (LC) and cells in the dorsal nucleus of the vagus or in the sympathetic ganglia. Peripheral sympathetic denervation (loss of cardiac or celiac fibers) has been proposed to be an early marker for PD (Braak et al. 2003).

Among the various NTFs studied, the glial cell linederived neurotrophic factor (GDNF) is the one more closely associated with $\mathrm{PD}$, due to its potent trophic action on cultured DA neurons (Lin et al. 1993). GDNF is produced by striatal neurons and is necessary for maintenance of adult nigrostriatal DA neurons and other central and peripheral nuclei affected in PD (Pascual et al. 2008). In addition, administration of exogenous GDNF can prevent neurotoxic damage of midbrain DA neurons (Tomac et al. 1995a,b) and noradrenergic neurons in the LC (Arenas et al. 1995) as well. Hence, stimulation of endogenous GDNF production and/or administration of exogenous GDNF are considered therapeutic strategies of potential applicability in PD (Gill et al. 2003, Vastag 2010).

In this review, we briefly summarize the current knowledge on the role of GDNF in dopamine/catecholamine neuron maintenance during adulthood, emphasizing the data obtained from animal models of NTF deficiency.

\section{GDNF signaling in central catecholaminergic neurons}

GDNF is a distantly related member of the transforming growth factor- $\beta$ (TGF- $\beta$ ) superfamily (Lin et al. 1993). Three GDNF homologues have been described so far, which include neurturin, persephin, and artemin. GDNF has raised special attention due to its potent effect on DA and noradrenergic neuron survival (Arenas et al. 1995, Gash et al. 1996; for a comprehensive review, see Kirik et al. 2004). The members of the GDNF family of trophic factors are often grouped as 'dopaminotrophic' factors. GDNF is expressed in several regions of the adult rodent brain, particularly in the striatum, anteroventral and anteromedial nuclei of the thalamus, and septum (Trupp et al. 1997, Pascual et al. 2008; Fig. 1), brain areas that receive prominent catecholaminergic afferent innervation (Lindvall \& Stenevi 1978, Bjorklund \& Hokfelt 1984). The identity of the striatal neurons expressing GDNF is not
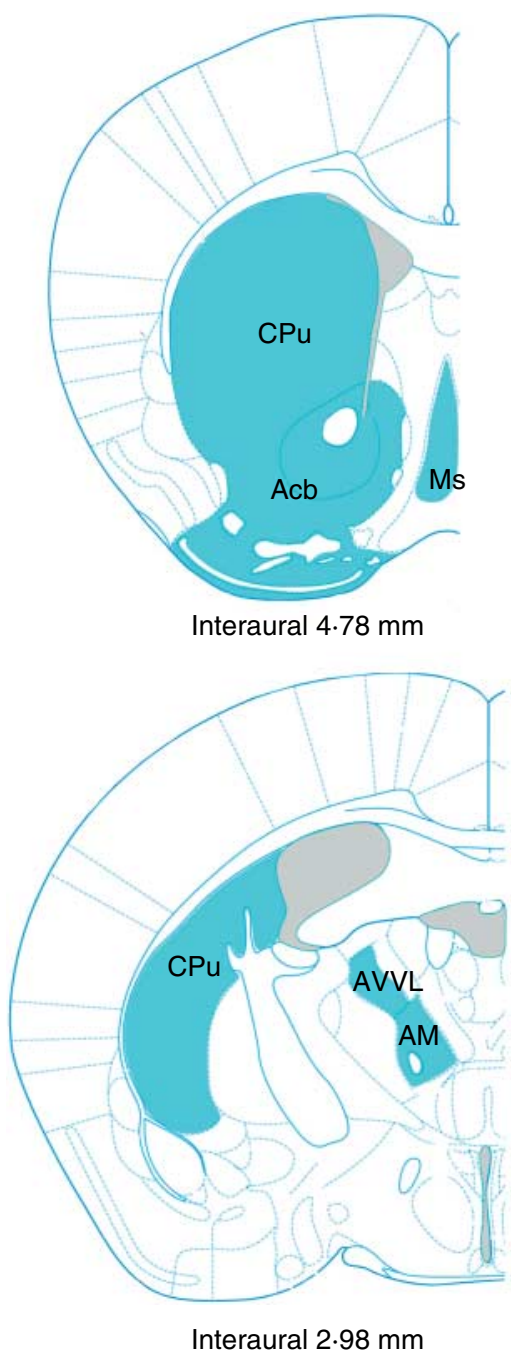

Figure 1 Schematic representation of regions with high GDNF expression levels in adult brains. Light blue represents the areas where GDNF mRNA or activity of the GDNF promoter is detected. $\mathrm{CPu}$, caudate putamen (striatum); Acb, accumbens nucleus; Ms, medial septal nucleus; AVVL, anteroventral thalamic nucleus, ventrolateral part; $\mathrm{AM}$, anteromedial thalamic nucleus. Ventricles are shown in gray.

completely defined. Striatal cholinergic interneurons produce GDNF, but other unidentified neuronal types also contribute to GDNF production in this nucleus (Bizon et al. 1999). The site and mechanisms of GDNF release as well as the signals regulating GDNF production are also basically unknown. Stimulation of GDNF expression levels by neurotransmitters (mainly dopamine and adenosine) and inflammatory signals and the underlying mechanisms have been investigated (for a review, see Saavedra et al. 2008). A recent in vitro study has revealed the secretory pathways used by specific GDNF isoforms and the modulation of its release by KCl-induced depolarization (LonkaNevalaita et al. 2010). In addition, the proteases that 
seem to be involved in GDNF maturation have been described, which is different from the processing pathway of NGF and BDNF (Lonka-Nevalaita et al. 2010).

As other NTFs, GDNF is uptaken by axon terminals of projecting neurons and transported to cell soma (for a review on retrograde transport, see Ibanez 2007). Injection of ${ }^{125}$ I-GDNF in striatum results in labeled cells in the ipsilateral SN and VTA, thus suggesting a trophic role of GDNF in adult nigrostriatal and mesolimbic neurons (Tomac et al. 1995b).

GDNF signals through extracellular GPI-anchored receptors (GFR $\alpha 1-4)$. GDNF have stronger binding activity over GFR $\alpha 1$ but can signal using the other receptors, although with smaller affinity (Trupp et al. 1998). Two GDNF-GFR $\alpha 1$ complexes recruit a dimer of the tyrosine kinase transmembrane protein (RET) (Durbec et al. 1996, Jing et al. 1996, Trupp et al. 1996; Fig. 2). Both GFR $\alpha 1$ and RET receptors present a wider distribution in brain than GDNF, suggesting that GDNF is able to diffuse to contact with not directly adjacent neuronal populations (Trupp et al. 1997). The presence in several brain regions of only one of the two preferred co-receptors is also striking (see below). GDNF activation of trans-phosphorylation of specific tyrosine residues of RET modulates several intracellular cascades. The pathways activated by RET have been principally studied in embryonic dopamine mesencephalic cells and perinatal sympathetic neurons; however, the mechanisms directly regulated by RET in adult catecholaminergic cells are poorly known. In sympathetic neurons, PI3K/Akt, Src-family kinases, and Erk pathways are activated after GDNF binds to its receptor. These pathways are also activated by other NTFs, leading to neurite outgrowth and neuronal survival (Kaplan \& Miller 2000), bringing into question whether different cell types require specific sets of NTFs, or there is a certain degree of redundancy in neurotrophism. Several arguments support GDNF specificity, including its highly restricted expression pattern (Fig. 1); the fact that different cell types require activation by GDNF of distinct intracellular pathways to elicit the same cellular processes and that although signaling by GDNF shows some degree of coincidence with other NTFs, clear dissimilarities are also appreciated (Airaksinen \& Saarma 2002). Furthermore, selective removal of GDNF in adult life leads to cell death in specific brain areas (see below). Several modulators of the GDNF/GFR $\alpha 1 /$ RET pathway have been described. Lipid rafts, a special membrane domain where signaling processes are concentrated, are enriched in GPI-anchored proteins like GFR $\alpha 1$. Upon GDNF stimulation, RET is recruited to lipid rafts, having different signaling partners in each cell compartment (Paratcha \& Ibanez 2002). TGF- $\beta$ is also a modulator of GDNF signaling, contributing to the functional translocation of GFR $\alpha 1$ to cell membrane in several cell types (Krieglstein et al. 1998, Peterziel et al. 2002). GDNF protective action over DA neurons in a MPTP mouse model requires both TGF- $\beta$ and GDNF, indicating that the cooperative prosurvival effects of both molecules are conserved during adulthood (Schober et al. 2007). The prosurvival effect of TGF- $\beta$ / GDNF over primary neurons relies on ERK/MAPK pathway and does not require PI3K activity (Peterziel et al. 2002). Heparin sulfate glycosaminoglycans, like syndecans, contribute to modulate the amount of GDNF required for receptor activation. Proteoglycans concentrate GDNF close to GFR $\alpha 1$ and RET receptors, optimizing signal transduction efficiency (reviewed by Sariola \& Saarma 2003).

GFR $\alpha 1$ and RET expression patterns are not fully overlapping (Trupp et al. 1997). This observation has lead to the search of alternative GDNF receptors. Several non-canonical forms of GDNF signaling have

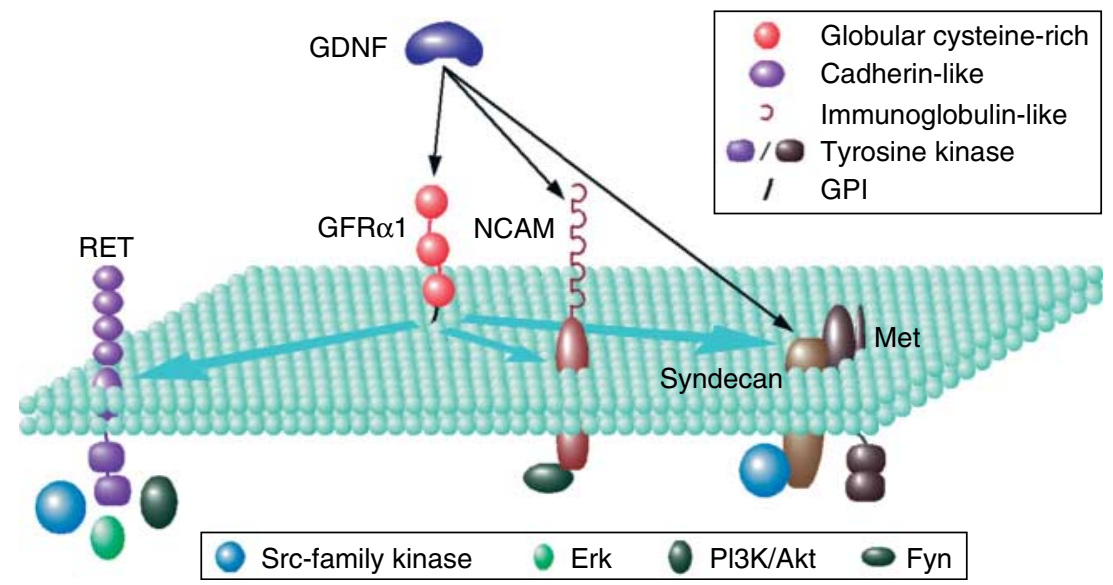

Figure 2 Schematic representation of GDNF signaling pathways. Arrows indicate interactions and boxes contain receptor protein domains (top) and cytoplasmic proteins (bottom). Protein domains are not represented scaled. 
been described in the adult rodent brain. In the absence of RET, GDNF induces phosphorylation of ERK/MAPK, PLC- $\gamma$, and CREB, and Src-family kinases and Fos activation (Poteryaev et al. 1999, Trupp et al. 1999). Met, a tyrosine kinase receptor for the hepatocyte growth factor, has been proposed as a contributor of this RET-independent GDNF signaling. Met activation can be modulated by GDNF using syndecans and the associated Src-type kinase pathway (Fig. 2; Popsueva et al. 2003). Another proposed mechanism for RETindependent signaling relies on the neural cell adhesion molecule (NCAM), a protein belonging to immunoglobulin superfamily (Paratcha et al. 2003). GDNF interacts with low affinity with NCAM but shifts to a high-affinity binding in the presence of GFR $\alpha 1$. NCAM respond to GDNF by activating similar pathways to those elicited by homophilic interactions, including activation of Fyn kinase (Paratcha et al. 2003). GDNF regulates neuronal morphology, cell migration, and synapse formation through the NCAM/GFR $\alpha 1$ complex (for a recent review, see Ibanez 2010). In DA neurons of the $\mathrm{SN}$, integrin $\alpha \mathrm{V}$ and NCAM may mediate the phenotypic changes associated with GDNF stimulation in vitro and in vivo (Chao et al. 2003). Recently, it has also been suggested that integrin $\beta 1$, other cell adhesion molecule, is involved in GDNF signaling (Cao et al. 2008). A ligand-induced cell adhesion mechanism has also been proposed for trans-cellular interaction of GFR $\alpha 1$ molecules in the presence of GDNF. This mechanism has been described in hippocampal neurons and it remains to be determined where it is also of functional relevance for adult DA neurons (Ledda et al. 2007).

GDNF has been shown to activate molecules related with the promotion of antioxidant defense and neuronal survival (for a review, see Saavedra et al. 2008). Among these pathways, the PI3K/AKT cascade (Neff et al. 2002) can protect neurons through several mechanisms including inactivation of apoptotic proteins (Dudek et al. 1997, Soler et al. 1999). GDNF over-expression (using lentiviral infection or engineered GDNF-producing cells) protects catecholaminergic neurons from toxic damage and induces fiber outgrowth in vivo (Arenas et al. 1995, Tomac et al. 1995a, Gash et al. 1996, Choi-Lundberg et al. 1997). However, the molecular mechanisms underlying these functional effects are still largely unknown. Recently, it has been reported that lentiviral GDNF delivered to the rat striatum induces gene expression in the $\mathrm{SN}$, notably tyrosine hydroxylase (TH), GTP cyclohydrolase-I (which catalyzes the synthesis of a cofactor of $\mathrm{TH}$, tetrahydrobiopterin), GDNF receptors, and Dlk-1 (a factor involved in cell proliferation and differentiation). As GDNF receptors are located in terminals of SN neurons, it is presumed that these genes are up-regulated in DA SN neurons in response to GDNF activation (Christophersen et al. 2007).

In recent years, several reports have investigated the role of GDNF in regulating mesolimbic circuits. Dopamine neurons in VTA express high levels of RET and GFR $\alpha 1$, and GDNF is produced in the nucleus accumbens, a VTA target region (Trupp et al. 1997). Infusion of GDNF in VTA blocks the ability of some drugs (cocaine and morphine) to stimulate biochemical changes at the mesolimbic pathway (Messer et al. 2000). These observations, suggesting a role of GDNF as a blocker of the effect of psychostimulants, have been extended to other drugs of abuse like opioids and ethanol (for a review, see Carnicella \& Ron 2009). The mechanisms operating to prevent drug-related phenotypes include the activation of MAPK, PI3K, and PLCr (Carnicella \& Ron 2009). In addition to these well-established signaling pathways, GDNF prevents ethanol-mediated association of $\mathrm{TH}$ with the chaperone heat-shock protein 90 , leading to a restoration of TH protein levels (He \& Ron 2008). In any event, GDNFdependent signaling pathways in brain are, as yet, poorly studied and the GDNF-mediated mechanisms required for the maintenance of adult catecholaminergic neurons remain essentially unknown.

\section{Genetic models of GDNF depletion}

Most of the knowledge available on the physiological function of GDNF has come from the analysis of genetically modified mice models. It is more than 15 years since three groups independently reported that ablation of the GDNF gene ( $G d n f^{-/}$mice) results in animal death after birth due to renal agenesis and the absence of the enteric plexus (Moore et al. 1996, Pichel et al. 1996, Sanchez et al. 1996). Unexpectedly, the $G d n f^{-/-}$mice exhibited an apparently normal number and organization of mesencephalic DA neurons. Embryonic (E14) slice cultures from wt and $G D N F^{-1}$ animals have shown that, in the absence of GDNF, the neurite outgrowth is inhibited without affecting neuronal survival in vitro (af Bjerken et al. 2007). These observations suggest that the trophic dependence of nigrostriatal neurons on GDNF, supported by the pharmacological experiments (exogenous administration of the trophic factor), might be acquired during postnatal maturation. In support of this view is the fact that blocking GDNF function by injection of neutralizing antibodies enhances cell death during the first period of naturally occurring apoptosis in the SN (Oo et al. 2003). In addition, striatal GDNF expression leads to a transient increase in SN cell number and a permanent augmentation in the number of VTA neurons (Kholodilov et al. 2004). 
Heterozygous $G d n f$ mice are fully viable and develop normally, showing few behavioral alterations during the first postnatal weeks. A group has reported impairment of a hippocampal formation-dependent memory task in 4-8-month old $G d n f^{+/-}$animals, without alterations in the nigrostriatal pathway (Gerlai et al. 2001). However, memory alterations in animal models of GDNF deficiency have not been analyzed in detail. Partial GDNF deficiency has been associated with a worsening of the phenotypes caused by chronic administration of the drug of abuse, a fact that has lead to the proposal of GDNF as a potential target to treat addition (for a review, see Carnicella \& Ron 2009). Spontaneous motor activity and coordination decline associated with age in heterozygous GDNF animals (Table 1; Boger et al. 2006). This behavioral alteration is paralleled with a small decrease of TH-positive SN neurons at 12 months of age and differences in striatal $\mathrm{TH}^{+}$fiber density with respect to controls (Boger et al. 2006). Embryonic GDNF deficit predisposes $G d n f^{+/-}$mice to higher susceptibility to catecholaminergic neurotoxins when compared with wild-type littermates (Boger et al. 2007). Similar results have been reported in aged GFR $\alpha 1^{+/-}$ mice (Table 1; Boger et al. 2008, Zaman et al. 2008).

Genetic deletion of the GDNF receptor RET in DA neurons has produced discordant reports regarding the role of this pathway in maintenance of neurons during adulthood. In a first report, no differences in adult (6-12 months of age) DA nigrostriatal neuronal numbers have been observed when RET was conditionally removed from DA neurons, as determined by comparative morphometric and biochemical analysis (Jain et al. 2006). However, a second study using the same genetic approximation has been able to detect a significant decrease of $\mathrm{TH}^{+} \mathrm{SN}$ neurons and striatal fiber density of RET aged mice. Conditional RET deletion did not compromise the viability of neurons in the VTA and LC (Table 1; Kramer et al. 2007). The variable results obtained with the regional RET-null mouse might be related to the fact that, as discussed above, GDNF can signal through 'non-canonical' N-CAM receptors (Paratcha et al. 2003), besides the Grf $\alpha 1 /$ RET pathway, that may compensate for the absence of RET. In both the studies, the Cre line removes RET during embryonic development, a situation that can lead to up-regulation of other GDNF receptors or NTFs. In addition, the study by Jain $e t$ al. (2006) could have been hampered by the fact that they pooled animals from $6-8$ to 12 months of age in their analysis, which could dilute the subtle differences found by Kramer et al. (2007) in 12-month-old animals.

To address the physiological role of GDNF in catecholaminergic central neurons, we have recently developed a conditional GDNF-null mouse where GDNF expression can be reduced during adulthood, avoiding adaptive compensatory mechanisms that can
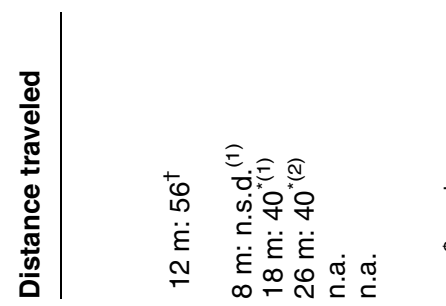

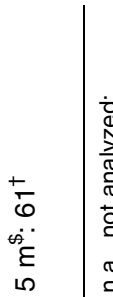

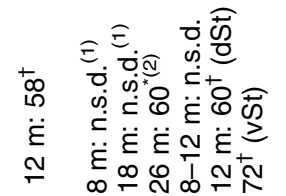

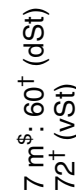

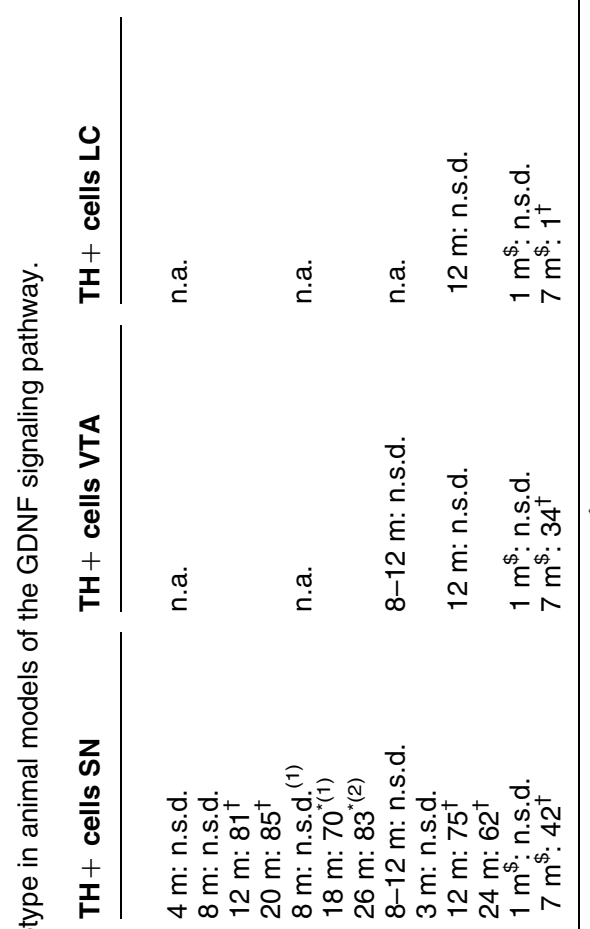



$\sin ^{2}+\sin ^{2} \pi$

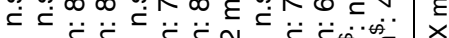

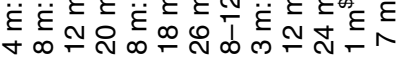

\section{1}

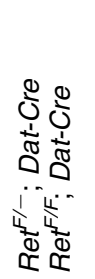

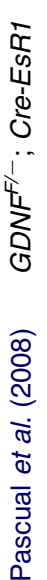

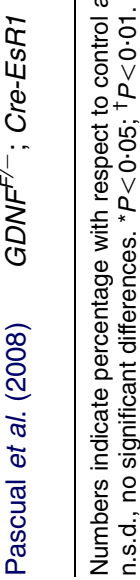


occur during development (Pascual et al. 2008). A selective and extensive catecholaminergic neuronal death, most notably in the LC, SN, and VTA, was observed in the conditional GDNF-deficient mice (Table 1 and Fig. 3A). These mice present a catecholaminergic selective phenotype, as other neuronal types analyzed (GABAergic and cholinergic) appear to be unaffected. Other TH-containing neurons, including those in the arcuate nucleus (AN), are not affected by the absence of GDNF, and phenotypes associated with hypothalamic or hypophyseal dysfunction were not observed in the cGDNF animals. The AN is a DA center at the hypothalamus-hypophyseal axis with the peculiarity of having dissociated the synthesis of DA. A significant number of AN neurons produce only one

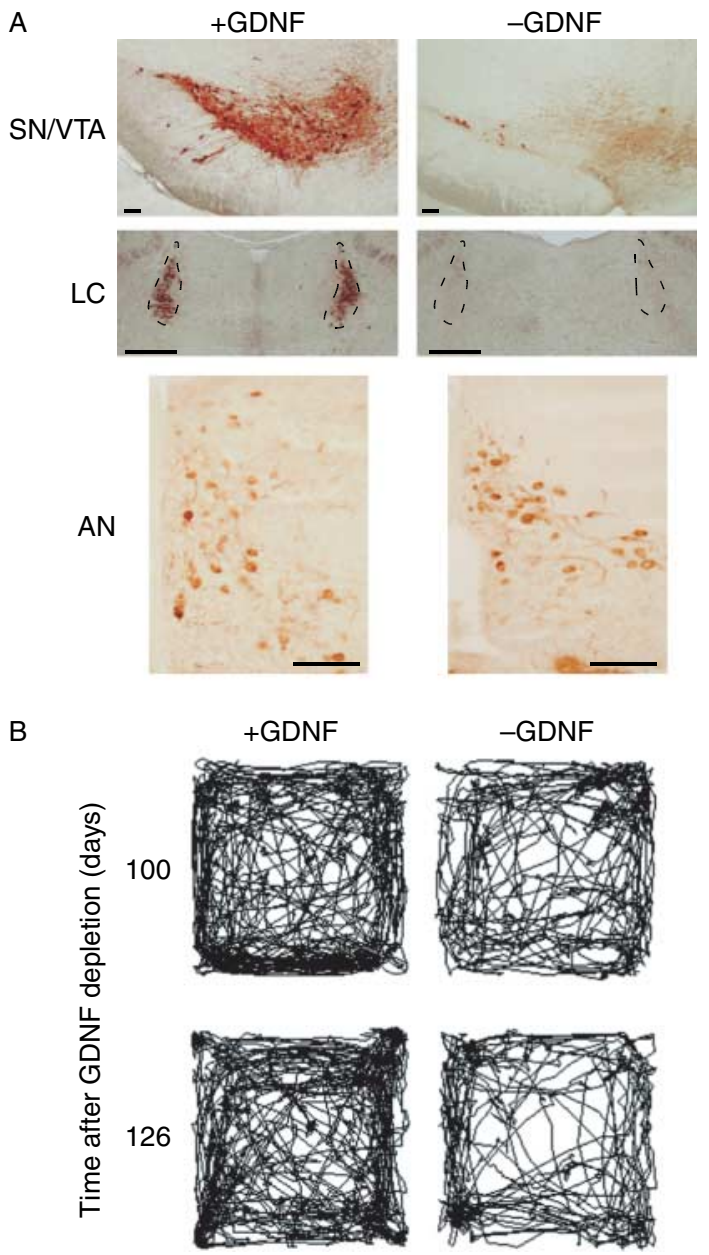

Figure 3 Catecholaminergic phenotype after genetic GDNF downregulation in the adult conditional GDNF mice (cGDNF). (A) Histological analysis of cGDNF animals 7 months after GDNF depletion. A marked cell death was observed in substantia nigra (SN), ventral tegmental area (VTA), and, particularly, in locus coeruleus (LC). Scale bars, $100 \mu \mathrm{m}$. (B) Behavioral analysis of adult GDNF-depleted mice. Spontaneous activity in open field (distance traveled) is recorded. of the enzymes required for DA synthesis (Ugrumov 2009), being the production of DA, a cooperative task involving several neuronal subpopulations. The neurochemical and histological alterations in GDNF-deprived mice leads to the development of behavioral motor abnormalities characterized by a progressive hypokinetic syndrome (Fig. 3B). These data have demonstrated that endogenous GDNF is absolutely required for trophic maintenance of specific DA and noradrenergic neurons. The GDNF-deficient mouse is a well-defined model for studying neuroprotection in experimental PD. The GDNF-controlled molecules that are required for mammalian SN, VTA, and LC neuronal survival remain to be defined.

\section{Clinical effects of GDNF}

For several decades, dopamine cell replacement (most frequently intrastriatal transplantation of DA-producing fetal midbrain neurons) has been considered as an experimental therapeutic approach to advanced PD, once pharmaceutical drugs have ceased to provide clinical benefit (Lindvall et al. 1990, Freed et al. 1992, Piccini et al. 1999). The actual clinical efficacy of DA-cell replacement, although as yet a matter not completely settled, has been seriously questioned by controlled, double-blinded clinical trials (Freed et al. 2001, Olanow et al. 2003). Therefore, as an alternative therapeutic strategy to DA-cell replacement, the interest has shifted to the intrastriatal delivery of NTFs that could 'protect' nigrostriatal neurons and thus halt or retard PD progression (Deierborg et al. 2008, Vastag 2010). The prototypical 'neuroprotective' agent used in most preclinical and clinical studies is GDNF that, as commented in previous sections, has demonstrated a remarkable trophic effect on mesencephalic DA neurons in vitro (Lin et al. 1993) and in vivo (Tomac et al. 1995a,b; for a review, see Kirik et al. 2004).

The good results obtained in the preclinical studies regarding the neuroprotective role of GDNF on catecholaminergic neurons have stimulated the development of clinical trials designed to test the therapeutic effects of GDNF in advanced PD patients. Some groups have assayed the effect of intrastriatal transplantation of GDNF-producing cells, such as those in the carotid body, with moderate results (Arjona et al. 2003). Currently, in vitro carotid body expansion is being tested using animal (Pardal et al. 2007) and human tissue to increase the number of cells available for transplantation (see Minguez-Castellanos et al. 2007). In parallel with these 'cell therapy' studies, several clinical trials have been performed using the direct intracerebral infusion of GDNF. In a controlled clinical trial, monthly intraventricular GDNF injection failed to provide clinical benefit in advanced PD 
patients and instead resulted in frequent adverse events (Nutt et al. 2003). A post-mortem examination in one patient suggested that GDNF did not reach the target cells via this route. However, encouraging clinical and neurochemical results were observed with continuous intraputaminal GDNF infusion on PD patients in two independent open-label clinical trials. One of the trials performed on five PD patients reported favorable clinical outcomes at 1 year, whereas $\left[{ }^{18} \mathrm{~F}\right]$-dopa PET studies showed an increase in putaminal uptake around the tip of each catheter (Gill et al. 2003). The second study on ten patients using a different delivery protocol also reported positive results at 6 months (Slevin et al. 2005). However, a randomized placebo-controlled trial involving $34 \mathrm{PD}$ patients showed no significant clinical differences between groups at 6 months, despite increased $\left[{ }^{18} \mathrm{~F}\right]$-dopa uptake in the recombinant GDNF-treated group (Lang et al. 2006). The openlabel extension of this study was halted due to safety concerns: three patients developed neutralizing antibodies, which could potentially cross-react with endogenous GDNF, whereas in a parallel toxicology study, some monkeys developed cerebellar damage. Besides GDNF, other members of the same protein family (particularly neurturin) are also being assayed in pilot clinical trials with as yet inconclusive results.

\section{Concluding remarks}

NTFs exert a potent effect on the survival and maintenance of phenotype in adult neurons, therefore intracerebral administration of these factors is a promising therapeutic strategy in neurodegenerative disorders, such as PD, presenting progressive neuronal death. There is a vast scientific literature supporting the neuroprotective role of exogenous GDNF on the nigrostriatal pathway. However, most of the clinical trials performed to test the efficacy of NTF-based therapies in advanced PD patients have been quite discouraging. The generation of the conditional GDNFnull mouse model has recently allowed us to show the absolute requirement of GDNF for survival of DA and noradrenergic neurons in adult brain. These data unequivocally demonstrate a major physiological neuroprotective effect of GDNF and therefore it should reanimate the interest in GDNF-based therapies. Interestingly, DA neurons in the hypothalamus appear to be unaffected by GDNF retrieval.

Clinical application of NTFs is confronted with several technological and scientific challenges that should be addressed in future preclinical and clinical research. Before new clinical trials are performed, a safe and efficacious route of GDNF delivery (either produced in cells, purified, or encoded in viral vectors) must be clearly established. In this regard, diffusion of
GDNF in the brain parenchyma and the appropriate concentration of GDNF delivered to cells are critical issues that might determine the clinical outcome. It must also be investigated whether the administration of appropriate cocktails of several trophic factors offer advantages over the use of GDNF alone. Besides these technologically oriented studies, much research should be done to unravel the actual physiological role of GDNF, and other NTFs, and their molecular mechanism of action on adult central neurons. This work might eventually lead to the identification of new signaling pathways that will provide targets accessible to small molecules amenable for their use as pharmaceutical drugs. The molecular physiology and pharmacology of neuroprotection are still at their infancy. Therefore, it can be presumed that the development of these fields will surely offer new opportunities for a more effective fight against PD and other neurodegenerative diseases.

\section{Declaration of interest}

The authors declare that there is no conflict of interest that could be perceived as prejudicing the impartiality of the research reported.

\section{Funding}

Research in the authors' laboratories is supported by the grants from the Marcelino Botin Foundation, the Ministry of Science and Innovation, and the Andalusian Government. Authors are members of TERCEL (ISCIII and FEDER).

\section{References}

Airaksinen MS \& Saarma M 2002 The GDNF family: signaling, biological functions and therapeutic value. Nature Reviews. Neuroscience 3 383-394. (doi:10.1038/nrn812)

Arenas E, Trupp M, Akerud P \& Ibanez CF 1995 GDNF prevents degeneration and promotes the phenotype of brain noradrenergic neurons in vivo. Neuron 15 1465-1473. (doi:10.1016/0896-6273(95) 90024-1)

Arjona V, Minguez-Castellanos A, Montoro RJ, Ortega A, Escamilla F, Toledo-Aral JJ, Pardal R, Mendez-Ferrer S, Martin JM, Perez M et al. 2003 Autotransplantation of human carotid body cell aggregates for treatment of Parkinson's disease. Neurosurgery 53 321-328 (discussion 328-330). (doi:10.1227/01.NEU.0000073315.88827.72)

Bizon JL, Lauterborn JC \& Gall CM 1999 Subpopulations of striatal interneurons can be distinguished on the basis of neurotrophic factor expression. Journal of Comparative Neurology 408 283-298. (doi:10.1002/(SICI) 1096-9861(19990531)408:2<283::AIDCNE9 > 3.0.CO;2-2)

af Bjerken S, Boger HA, Nelson M, Hoffer BJ, Granholm AC \& Stromberg I 2007 Effects of glial cell line-derived neurotrophic factor deletion on ventral mesencephalic organotypic tissue cultures. Brain Research 1133 10-19. (doi:10.1016/j.brainres.2006. 11.052)

Bjorklund A \& Hokfelt T 1984. Handbook of Chemical Neuroanatomy: Classical Neurotransmitters in the CNS, Part I, Amsterdam: Elsevier. 
Boger HA, Middaugh LD, Huang P, Zaman V, Smith AC, Hoffer BJ, Tomac AC \& Granholm AC 2006 A partial GDNF, depletion leads to earlier age-related deterioration of motor function and tyrosine hydroxylase expression in the substantia nigra. Experimental Neurology 202 336-347. (doi:10.1016/j.expneurol.2006.06.006)

Boger HA, Middaugh LD, Patrick KS, Ramamoorthy S, Denehy ED, Zhu H, Pacchioni AM, Granholm AC \& McGinty JF 2007 Long-term consequences of methamphetamine exposure in young adults are exacerbated in glial cell line-derived neurotrophic factor heterozygous mice. Journal of Neuroscience 27 8816-8825. (doi:10.1523/ JNEUROSCI.1067-07.2007)

Boger HA, Middaugh LD, Zaman V, Hoffer B \& Granholm AC 2008 Differential effects of the dopamine neurotoxin MPTP in animals with a partial deletion of the GDNF receptor, GFR alphal, gene. Brain Research 1241 18-28. (doi:10.1016/j.brainres.2008.09.011)

Braak H, Del Tredici K, Rub U, de Vos RA, Jansen Steur EN \& Braak E 2003 Staging of brain pathology related to sporadic Parkinson's disease. Neurobiology of Aging 24 197-211. (doi:10.1016/S0197-4580 (02) 00065-9)

Cajal SR 1928. Degeneration and Regeneration of the Nervous System, London: Oxford University Press.

Cao JP, Yu JK, Li C, Sun Y, Yuan HH, Wang HJ \& Gao DS 2008 Integrin betal is involved in the signaling of glial cell line-derived neurotrophic factor. Journal of Comparative Neurology 509 203-210. (doi:10.1002/cne.21739)

Carnicella S \& Ron D 2009 GDNF - a potential target to treat addiction. Pharmacology and Therapeutics 122 9-18. (doi:10.1016/j. pharmthera.2008.12.001)

Chao CC, Ma YL, Chu KY \& Lee EH 2003 Integrin alphav and NCAM mediate the effects of GDNF on DA neuron survival, outgrowth, DA turnover and motor activity in rats. Neurobiology of Aging 24 105-116. (doi:10.1016/S0197-4580(02)00047-7)

Choi-Lundberg DL, Lin Q, Chang YN, Chiang YL, Hay CM, Mohajeri H, Davidson BL \& Bohn MC 1997 Dopaminergic neurons protected from degeneration by GDNF gene therapy. Science $\mathbf{2 7 5} 838-841$. (doi:10.1126/science.275.5301.838)

Christophersen NS, Gronborg M, Petersen TN, Fjord-Larsen L, Jorgensen JR, Juliusson B, Blom N, Rosenblad C \& Brundin P 2007 Midbrain expression of Delta-like 1 homologue is regulated by GDNF and is associated with dopaminergic differentiation. Experimental Neurology 204 791-801. (doi:10.1016/j.expneurol.2007. 01.014)

Dauer W \& Przedborski S 2003 Parkinson's disease: mechanisms and models. Neuron 39 889-909. (doi:10.1016/S0896-6273(03) 00568-3)

Deierborg T, Soulet D, Roybon L, Hall V \& Brundin P 2008 Emerging restorative treatments for Parkinson's disease. Progress in Neurobiology 85 407-432. (doi:10.1016/j.pneurobio.2008.05.001)

Dudek H, Datta SR, Franke TF, Birnbaum MJ, Yao R, Cooper GM, Segal RA, Kaplan DR \& Greenberg ME 1997 Regulation of neuronal survival by the serine-threonine protein kinase Akt. Science $\mathbf{2 7 5}$ 661-665. (doi:10.1126/science.275.5300.661)

Durbec P, Marcos-Gutierrez CV, Kilkenny C, Grigoriou M, Wartiowaara K, Suvanto P, Smith D, Ponder B, Costantini F, Saarma M et al. 1996 GDNF signaling through the Ret receptor tyrosine kinase. Nature 381 789-793. (doi:10.1038/381789a0)

Fahn S 2003 Description of Parkinson's disease as a clinical syndrome. Annals of the New York Academy of Sciences 991 1-14. (doi:10.1111/j. 1749-6632.2003.tb07458.x)

Farrer MJ 2006 Genetics of Parkinson disease: paradigm shifts and future prospects. Nature Reviews. Genetics 7 306-318. (doi:10.1038/ nrg1831)

Freed CR, Breeze RE, Rosenberg NL, Schneck SA, Kriek E, Qi JX, Lone T, Zhang YB, Snyder JA \& Wells TH 1992 Survival of implanted fetal dopamine cells and neurologic improvement 12 to 46 months after transplantation for Parkinson's disease. New England Journal of Medicine 327 1549-1555. (doi:10.1056/NEJM199211263272202)

Freed CR, Greene PE, Breeze RE, Tsai WY, DuMouchel W, Kao R, Dillon S, Winfield H, Culver S, Trojanowski JQ et al. 2001
Transplantation of embryonic dopamine neurons for severe Parkinson's disease. New England Journal of Medicine 344 710-719. (doi:10.1056/NEJM200103083441002)

Gash DM, Zhang Z, Ovadia A, Cass WA, Yi A, Simmerman L, Russell D, Martin D, Lapchak PA, Collins F et al. 1996 Functional recovery in parkinsonian monkeys treated with GDNF. Nature 380 252-255. (doi:10.1038/380252a0)

Gerlai R, McNamara A, Choi-Lundberg DL, Armanini M, Ross J, Powell-Braxton L \& Phillips HS 2001 Impaired water maze learning performance without altered dopaminergic function in mice heterozygous for the GDNF mutation. European Journal of Neuroscience 14 1153-1163. (doi:10.1046/j.0953-816x.2001.01724.x)

Gill SS, Patel NK, Hotton GR, O'Sullivan K, McCarter R, Bunnage M, Brooks DJ, Svendsen CN \& Heywood P 2003 Direct brain infusion of glial cell line-derived neurotrophic factor in Parkinson disease. Nature Medicine 9 589-595. (doi:10.1038/nm850)

Hamburger V \& Levi-Montalcini R 1949 Proliferation, differentiation and degeneration in the spinal ganglia of the chick embryo under normal and experimental conditions. Journal of Experimental Zoology 111 457-501. (doi:10.1002/jez.1401110308)

He DY \& Ron D 2008 Glial cell line-derived neurotrophic factor reverses ethanol-mediated increases in tyrosine hydroxylase immunoreactivity via altering the activity of heat shock protein 90 . Journal of Biological Chemistry 283 12811-12818. (doi:10.1074/jbc. M706216200)

Ibanez CF 2007 Message in a bottle: long-range retrograde signaling in the nervous system. Trends in Cell Biology 17 519-528. (doi:10.1016/j. tcb.2007.09.003)

Ibanez CF 2010 Beyond the cell surface: new mechanisms of receptor function. Biochemical and Biophysical Research Communications 396 24-27. (doi:10.1016/j.bbrc.2010.01.136)

Jain S, Golden JP, Wozniak D, Pehek E, Johnson EM Jr \& Milbrandt J 2006 RET is dispensable for maintenance of midbrain dopaminergic neurons in adult mice. Journal of Neuroscience 26 11230-11238. (doi:10.1523/JNEUROSCI.1876-06.2006)

Jing S, Wen D, Yu Y, Holst PL, Luo Y, Fang M, Tamir R, Antonio L, Hu Z, Cupples R et al. 1996 GDNF-induced activation of the ret protein tyrosine kinase is mediated by GDNFR-alpha, a novel receptor for GDNF. Cell 85 1113-1124. (doi:10.1016/S0092-8674(00)81311-2)

Kaplan DR \& Miller FD 2000 Neurotrophin signal transduction in the nervous system. Current Opinion in Neurobiology 10 381-391. (doi:10. 1016/S0959-4388(00)00092-1)

Kholodilov N, Yarygina O, Oo TF, Zhang H, Sulzer D, Dauer W \& Burke RE 2004 Regulation of the development of mesencephalic dopaminergic systems by the selective expression of glial cell linederived neurotrophic factor in their targets. Journal of Neuroscience 24 3136-3146. (doi:10.1523/JNEUROSCI.4506-03.2004)

Kirik D, Georgievska B \& Bjorklund A 2004 Localized striatal delivery of GDNF as a treatment for Parkinson disease. Nature Neuroscience 7 105-110. (doi:10.1038/nn1175)

Kramer ER, Aron L, Ramakers GM, Seitz S, Zhuang X, Beyer K, Smidt MP \& Klein R 2007 Absence of Ret signaling in mice causes progressive and late degeneration of the nigrostriatal system. PLoS Biology 5 e39. (doi:10.1371/journal.pbio.0050039)

Krieglstein K, Henheik P, Farkas L, Jaszai J, Galter D, Krohn K \& Unsicker K 1998 Glial cell line-derived neurotrophic factor requires transforming growth factor-beta for exerting its full neurotrophic potential on peripheral and CNS neurons. Journal of Neuroscience 18 9822-9834.

Lang AE \& Lozano AM 1998 Parkinson's disease. Second of two parts. New England Journal of Medicine 339 1130-1143. (doi:10.1056/ NEJM199810153391607)

Lang AE, Gill S, Patel NK, Lozano A, Nutt JG, Penn R, Brooks DJ, Hotton G, Moro E, Heywood P et al. 2006 Randomized controlled trial of intraputamenal glial cell line-derived neurotrophic factor infusion in Parkinson disease. Annals of Neurology 59 459-466. (doi:10.1002/ana.20737) 
de Lau LM \& Breteler MM 2006 Epidemiology of Parkinson's disease. Lancet Neurology 5 525-535. (doi:10.1016/S1474-4422(06)70471-9)

Ledda F, Paratcha G, Sandoval-Guzman T \& Ibanez CF 2007 GDNF and GFRalphal promote formation of neuronal synapses by ligandinduced cell adhesion. Nature Neuroscience 10 293-300. (doi:10. 1038/nn1855)

Lin LF, Doherty DH, Lile JD, Bektesh S \& Collins F 1993 GDNF: a glial cell line-derived neurotrophic factor for midbrain dopaminergic neurons. Science 260 1130-1132. (doi:10.1126/science.8493557)

Lindvall O \& Stenevi U 1978 Dopamine and noradrenaline neurons projecting to the septal area in the rat. Cell and Tissue Research 190 383-407. (doi:10.1007/BF00219554)

Lindvall O, Brundin P, Widner H, Rehncrona S, Gustavii B, Frackowiak R, Leenders KL, Sawle G, Rothwell JC \& Marsden CD 1990 Grafts of fetal dopamine neurons survive and improve motor function in Parkinson's disease. Science 247 574-577. (doi:10.1126/science. 2105529)

Lonka-Nevalaita L, Lume M, Leppanen S, Jokitalo E, Peranen J \& Saarma M 2010 Characterization of the intracellular localization, processing, and secretion of two glial cell line-derived neurotrophic factor splice isoforms. Journal of Neuroscience 30 11403-11413. (doi:10.1523/JNEUROSCI.5888-09.2010)

Messer CJ, Eisch AJ, Carlezon WA Jr, Whisler K, Shen L, Wolf DH, Westphal H, Collins F, Russell DS \& Nestler EJ 2000 Role for GDNF in biochemical and behavioral adaptations to drugs of abuse. Neuron 26 247-257. (doi:10.1016/S0896-6273(00)81154-X)

Minguez-Castellanos A, Escamilla-Sevilla F, Hotton GR, Toledo-Aral JJ, Ortega-Moreno A, Mendez-Ferrer S, Martin-Linares JM, Katati MJ, Mir P, Villadiego J et al. 2007 Carotid body autotransplantation in Parkinson disease: a clinical and PET study. Journal of Neurology, Neurosurgery, and Psychiatry 78 825-831. (doi:10.1136/jnnp.2006. 106021)

Moore MW, Klein RD, Farinas I, Sauer H, Armanini M, Phillips H, Reichardt LF, Ryan AM, Carver-Moore K \& Rosenthal A 1996 Renal and neuronal abnormalities in mice lacking GDNF. Nature 382 76-79. (doi:10.1038/382076a0)

Neff F, Noelker C, Eggert K \& Schlegel J 2002 Signaling pathways mediate the neuroprotective effects of GDNF. Annals of the New York Academy of Sciences 973 70-74. (doi:10.1111/j.1749-6632.2002. tb04608.x)

Nutt JG, Burchiel KJ, Comella CL, Jankovic J, Lang AE, Laws ER Jr, Lozano AM, Penn RD, Simpson RK Jr, Stacy M et al. 2003

Randomized, double-blind trial of glial cell line-derived neurotrophic factor (GDNF) in PD. Neurology 60 69-73.

Olanow CW, Goetz CG, Kordower JH, Stoessl AJ, Sossi V, Brin MF, Shannon KM, Nauert GM, Perl DP, Godbold J et al. 2003 A doubleblind controlled trial of bilateral fetal nigral transplantation in Parkinson's disease. Annals of Neurology 54 403-414. (doi:10.1002/ ana.10720)

Oo TF, Kholodilov N \& Burke RE 2003 Regulation of natural cell death in dopaminergic neurons of the substantia nigra by striatal glial cell line-derived neurotrophic factor in vivo. Journal of Neuroscience $\mathbf{2 3}$ 5141-5148.

Paratcha G \& Ibanez CF 2002 Lipid rafts and the control of neurotrophic factor signaling in the nervous system: variations on a theme. Current Opinion in Neurobiology 12 542-549. (doi:10.1016/ S0959-4388(02)00363-X)

Paratcha G, Ledda F \& Ibanez CF 2003 The neural cell adhesion molecule NCAM is an alternative signaling receptor for GDNF family ligands. Cell 113 867-879. (doi:10.1016/S0092-8674(03) 00435-5)

Pardal R, Ortega-Saenz P, Duran R \& Lopez-Barneo J J 2007 Glia-like stem cells sustain physiologic neurogenesis in the adult mammalian carotid body. Cell 131 364-377. (doi:10.1016/j.cell.2007.07.043)

Pascual A, Hidalgo-Figueroa M, Piruat JI, Pintado CO, Gomez-Diaz R \& Lopez-Barneo J 2008 Absolute requirement of GDNF for adult catecholaminergic neuron survival. Nature Neuroscience 11 755-761. (doi:10.1038/nn.2136)
Peterziel H, Unsicker K \& Krieglstein K 2002 TGFbeta induces GDNF responsiveness in neurons by recruitment of GFRalphal to the plasma membrane. Journal of Cell Biology 159 157-167. (doi:10.1083/ jcb.200203115)

Piccini P, Brooks DJ, Bjorklund A, Gunn RN, Grasby PM, Rimoldi O, Brundin P, Hagell P, Rehncrona S, Widner H et al. 1999 Dopamine release from nigral transplants visualized in vivo in a Parkinson's patient. Nature Neuroscience 2 1137-1140. (doi:10. $1038 / 16060)$

Pichel JG, Shen L, Sheng HZ, Granholm AC, Drago J, Grinberg A, Lee EJ, Huang SP, Saarma M, Hoffer BJ et al. 1996 Defects in enteric innervation and kidney development in mice lacking GDNF. Nature 382 73-76. (doi:10.1038/382073a0)

Popsueva A, Poteryaev D, Arighi E, Meng X, Angers-Loustau A, Kaplan D, Saarma M \& Sariola H 2003 GDNF promotes tubulogenesis of GFRalphal-expressing MDCK cells by Src-mediated phosphorylation of Met receptor tyrosine kinase. Journal of Cell Biology 161 119-129. (doi:10.1083/jcb.200212174)

Poteryaev D, Titievsky A, Sun YF, Thomas-Crusells J, Lindahl M, Billaud M, Arumae U \& Saarma M 1999 GDNF triggers a novel ret-independent Src kinase family-coupled signaling via a GPI-linked GDNF receptor alpha1. FEBS Letters 463 63-66. (doi:10.1016/S0014-5793(99)01590-2)

de Rijk MC, Tzourio C, Breteler MM, Dartigues JF, Amaducci L, LopezPousa S, Manubens-Bertran JM, Alperovitch A \& Rocca WA 1997 Prevalence of parkinsonism and Parkinson's disease in Europe: the EUROPARKINSON Collaborative Study. European Community Concerted Action on the Epidemiology of Parkinson's disease. Journal of Neurology, Neurosurgery, and Psychiatry 62 10-15. (doi:10. 1136/jnnp.62.1.10)

Saavedra A, Baltazar G \& Duarte EP 2008 Driving GDNF expression: the green and the red traffic lights. Progress in Neurobiology 86 186-215. (doi:10.1016/j.pneurobio.2008.09.006)

Sanchez MP, Silos-Santiago I, Frisen J, He B, Lira SA \& Barbacid M 1996 Renal agenesis and the absence of enteric neurons in mice lacking GDNF. Nature 382 70-73. (doi:10.1038/382070a0)

Sariola H \& Saarma M 2003 Novel functions and signaling pathways for GDNF. Journal of Cell Science 116 3855-3862. (doi:10.1242/jcs. 00786)

Schober A, Peterziel H, von Bartheld CS, Simon H, Krieglstein K \& Unsicker K 2007 GDNF applied to the MPTP-lesioned nigrostriatal system requires TGF-beta for its neuroprotective action. Neurobiology of Disease 25 378-391. (doi:10.1016/j.nbd.2006.10. 005)

Slevin JT, Gerhardt GA, Smith CD, Gash DM, Kryscio R \& Young B 2005 Improvement of bilateral motor functions in patients with Parkinson disease through the unilateral intraputaminal infusion of glial cell line-derived neurotrophic factor. Journal of Neurosurgery 102 216-222. (doi:10.3171/jns.2005.102.2.0216)

Soler RM, Dolcet X, Encinas M, Egea J, Bayascas JR \& Comella JX 1999 Receptors of the glial cell line-derived neurotrophic factor family of neurotrophic factors signal cell survival through the phosphatidylinositol 3-kinase pathway in spinal cord motoneurons. Journal of Neuroscience 19 9160-9169.

Tomac A, Lindquist E, Lin LF, Ogren SO, Young D, Hoffer BJ \& Olson L 1995a Protection and repair of the nigrostriatal dopaminergic system by GDNF in vivo. Nature 373 335-339. (doi:10. 1038/373335a0)

Tomac A, Widenfalk J, Lin LF, Kohno T, Ebendal T, Hoffer BJ \& Olson L $1995 b$ Retrograde axonal transport of glial cell line-derived neurotrophic factor in the adult nigrostriatal system suggests a trophic role in the adult. PNAS 92 8274-8278. (doi:10.1073/pnas. 92.18.8274)

Trupp M, Arenas E, Fainzilber M, Nilsson AS, Sieber BA, Grigoriou M, Kilkenny C, Salazar-Grueso E, Pachnis V \& Arumae U 1996 Functional receptor for GDNF encoded by the c-ret protooncogene. Nature 381 785-789. (doi:10.1038/381785a0) 
Trupp M, Belluardo N, Funakoshi H \& Ibanez CF 1997 Complementary and overlapping expression of glial cell line-derived neurotrophic factor (GDNF), c-ret proto-oncogene, and GDNF receptor-alpha indicates multiple mechanisms of trophic actions in the adult rat CNS. Journal of Neuroscience $\mathbf{1 7}$ 3554-3567.

Trupp M, Raynoschek C, Belluardo N \& Ibanez CF 1998 Multiple GPI-anchored receptors control GDNF-dependent and independent activation of the c-Ret receptor tyrosine kinase. Molecular and Cellular Neurosciences 11 47-63. (doi:10.1006/mcne.1998. 0667)

Trupp M, Scott R, Whittemore SR \& Ibanez CF 1999 Ret-dependent and -independent mechanisms of glial cell line-derived neurotrophic factor signaling in neuronal cells. Journal of Biological Chemistry 274 20885-20894. (doi:10.1074/jbc.274.30. 20885)
Ugrumov MV 2009 Non-dopaminergic neurons partly expressing dopaminergic phenotype: distribution in the brain, development and functional significance. Journal of Chemical Neuroanatomy 38 241-256. (doi:10.1016/j.jchemneu.2009.08.004)

Vastag B 2010 Biotechnology: crossing the barrier. Nature 466 916-918. (doi:10.1038/466916a)

Zaman V, Boger HA, Granholm AC, Rohrer B, Moore A, Buhusi M, Gerhardt GA, Hoffer BJ \& Middaugh LD 2008 The nigrostriatal dopamine system of aging GFRalpha-1 heterozygous mice: neurochemistry, morphology and behavior. European Journal of Neuroscience 28 1557-1568. (doi:10.1111/j.1460-9568.2008.06456.x)

Received in final form 23 February 2011

Accepted 28 February 2011

Made available online as an Accepted Preprint 28 February 2011 